\title{
Rancang Bangun Sistem Informasi Lembaga Penelitian dan Pengabdian Masyarakat Universitas Halu Oleo
}

\author{
Muhammad Nadzirin Anshari Nur ${ }^{1}$, Subardin ${ }^{2}$, Indrayati Galulu ${ }^{1}$, Asminar ${ }^{1}$ \\ ${ }^{1}$ Teknik Elektro, Universitas Halu Oleo, ${ }^{2}$ Teknik Informatika Universitas Halu Oleo \\ nadzirin@uho.ac.id,subardin@uho.ac.id \\ Coprespondent Author : Muhammad Nadzirin Anshari Nur
}

\begin{abstract}
Universities are required to carry out research and community service in addition to providing education as mandated by law, research and community service at Halu Oleo University are managed by LPPM, namely the Institute for Research and Community Service and LPPM must have an information system as a forum for delivering information to the Halu University community. Oleo, currently the LPPM information system already exists but has not been updated since the previous LPPM so it is necessary to design a new information system website, The purpose of this research is to design and build an information system that covers all institutional aspects at LPPM Halu Oleo University including research information and the latest service, announcements of acceptance of internal and external proposals, information on LPPM profiles and some other information that helps the community in conducting research and community service. The method used in this research is an information system design method with a waterfall model which starts from the method of analysis, design, implementation, testing, development and maintenance. /lppm.uho.ac.id.
\end{abstract}

Keyword - Information System, LPPM, Website

Abstrak - Perguruan tinggi berkewajiban menyelenggarakan penelitian dan pengabdian masyarakat disamping melaksanakan pendidikan sebagaimana diamanahkan oleh undang-undang, tata kelola peneletian dan pengabdian masyarakat pada Universitas Halu Oleo dikelola oleh LPPM yaitu Lembaga Penelitian dan Pengabdian Masyarakat dan seharusnya LPPM memiliki sebuah sistem informasi sebagai wadah penayampian informasi kepada sivitas Universitas Halu Oleo, saat ini sistem informasi LPPM sudah ada namun belum pernah terupdate sejak LPPM sebelumnya sehingga perlu melakukan rancang bangun website sistem informasi yang baru, Tujuan penelitian ini adalah untuk merancang dan membangun sebuah sistem informasi yang memuat seluruh aspek kelembagaan pada LPPM Universitas Halu Oleo termasuk informasi-informasi penelitian dan pengabdin terbaru, pengumuman penerimaan proposal internal maupun eksternal, informasi profil LPPM dan beberapa informasi lainnya yang membantu sivitas dalam pelaksanaan penelitian dan pengabdian masyarakat. Metode yang digunakan dalam penelitian ini yaitu metode perancangan sistem informasi dengan model waterfall dimana dimulai dari metode analisis, desain, implementasi, pengujian, pengembagan dan maintenance, Luaran yang dihasilkan dari penelitian ini adalah produk sistem informasi yang bisa diakses secara online melalui laman http://lppm.uho.ac.id.

Kata kunci — Sistem Informasi, LPPM, Website.

\section{PENDAHULUAN}

Perguruan tinggi berkewajiban menyelenggarakan penelitian dan pengabdian masyarakat disamping melaksanakan pendidikan sebagaimana diamanahkan oleh undang-undang Nomor 20 Tahun 2003 tentang Sistem Pendidikan Nasional Pasal 20 [1] , Pengelola Perguruan Tinggi (PT) diharapkan dapat memfasilitasi kegiatan penelitian dan pengabdian di lingkungan perguruan tinggi yang mereka ajar. Karena penelitian dan pengabdian kepada masyarakat sudah menjadi bagian yang penting dalam Tri Dharma PT. Penelitian dan pengabdian adalah salah satu yang harus ditunaikan oleh dosen untuk melengkapi syarat Tri Dharna.

Oleh sebab itu PT harus dapat terlibat aktif dalam kegiatan penelitian dan pengabdian. Hal tersebut diharapkan bisa menjadikan dosen lebih terpacu dalam meningkatkan kualitas diri dalam melakukan penelitian dan pengabdian[2] , Penelitian dan Pengabdian adalah merupakan implementasi dari komponen tri dharma perguruan tinggi yang merupakan tugas pokok dosen. Untuk dosen penelitian, pengabdian kepada masyarakat merupakan salah satu elemen untuk kenaikan pangkat. Manfaatnya untuk institusi adalah untuk peningkatan Akreditasi, sedangkan manfaatnya bagi bangsa dan negara adalah hasil penelitian diharapkan dapat menjadi acuan untuk menetapkan arah dan kebijakan pemerintahan [3] .

LPPM ( Lembaga Penelitian dan Pengabdian pada Masyarakat ) adalah sebuah unit kegiatan yang berfungsi mengelola semua kegiatan penelitian dan pengabdian kepada masyarakat yang dilaksanakan oleh dosen dalam kaitan dengan peningkatan kapasistas dosen pada perguruan tinggi. [4] Pada saat ini data-data penelitian maupun pengabdian masih dikelola secara semi manual dan online dengan menggunakan aplikasi Microsoft excel serta pengiriman kinerja penelitian dosen melalui email. Pencatatan data dapat dilakukan pada banyak file yang berbeda yang dapat disimpan pada tempat yang berbeda. Hal ini membutuhkan waktu yang cukup lama pada saat melakukan editing terhadap data untuk menyusun laporan kinerja [4], selain itu kondisi website LPPM khususnya Universitas Halu Oleo belum terupdate sejak tahun 2016 sehingga perlu dilakukan redesain dalam bentuk rancang bangun sistem informasi lembaga penelitian dan pengabdian masyarakat Universitas Halu Oleo

\section{TINJAUAN PUSTAKA}

A. Pengertian Sistem Informasi 
Sistem informasi adalah sekumpulan sistem perangkat keras, perangkat lunak, prosedur dan atau aturan yang diorganisasikan secara menyeluruh untuk pengolahan data menjadi suatu informasi yang bermanfaat guna memecahkan suatu masalah dan pengambilan keputusan. Menurut O'Brien Sistem informasi merupakan sebuah kombinasi dari setiap unit yang dikelola orang, perangkat keras, perangkat lunak, jaringan komuniakasi data serta komputer, dan basis data yang mengubah, mengumpulkan, serta menyampaikan informasi [5]

\section{B. Konsep Dasar Web}

World Wide Web biasa disebut dengan web yang merupakan sebuah sistem yang interlinked (kumpulan link atau saluran yang saling terhubung), akses dokumen hypertext melalui internet (Salahuddin, 2008:4).

\section{Model Waterfall}

Model Waterfall adalah suatu proses perangkat lunak yang berurutan, dipandang sebagai terus mengalir kebawah (seperti air terjun) melewati fase-fase perencanaan, pemodelan, implementasi dan pengujian.[6]

Berikut ini adalah tahapan dari metode waterfall:

1. Analisis - Melakukan anlisi awal terhadap kebutuhan system perancangan website

2. Desain ,tahapan ini melakukan desain dan merancang system baik itu arsitektur, alur system serta tampilan website

3. Implementasi adalah tahapan membangu desain tersebut menjadi sebuah program dan mengimplementasikan

4. Testing

Melakukan pengujian terhadap system yang sudah dibangun

5. Develop pada tahapan ini jika terdapat permasalahan dari pengujian maka dilakukan perbaikan

6. Maintenance yaitu tahapan instalasi dan proses perbaikan sampai system selali selain itu pada proses ini dilakukan perawatan sistem. [6]

\section{METODE PENELITIAN}

Adapun gambaran sistem yang akan dirancang yaitu seperti pada gambar 1 :sesuai model waterfall

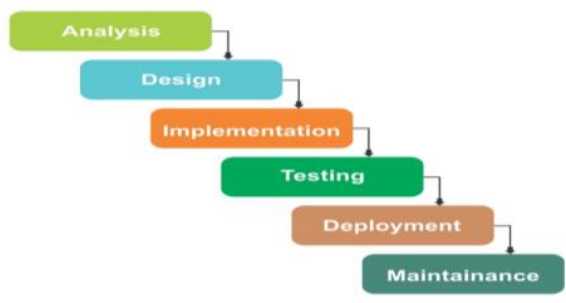

Gambar 1. Diagram Alir metode penelitian (Model waterfall)
Dalam gambar 1 Penelitian dimulai dengan tahapan analisys kebutuhan system pada tahapan ini melakukan survey untuk mengetahui kondisi awal serta kebutuhan pembuatan system informasi, setelah tahapan survey dan pengumpulan data dan analisis dilanjutkan proses desain dan perancangan system pada proses ini dilakukan desain diagram system, database serta software yang digunakan selanjutnya proses impelementasi atau proses coding seletah itu proses development dengan melakukan ujicoba tahap awal terakhir proses maintenance.

\section{A. Arsitektur Sistem / Peta Situs Sistem Informasi}

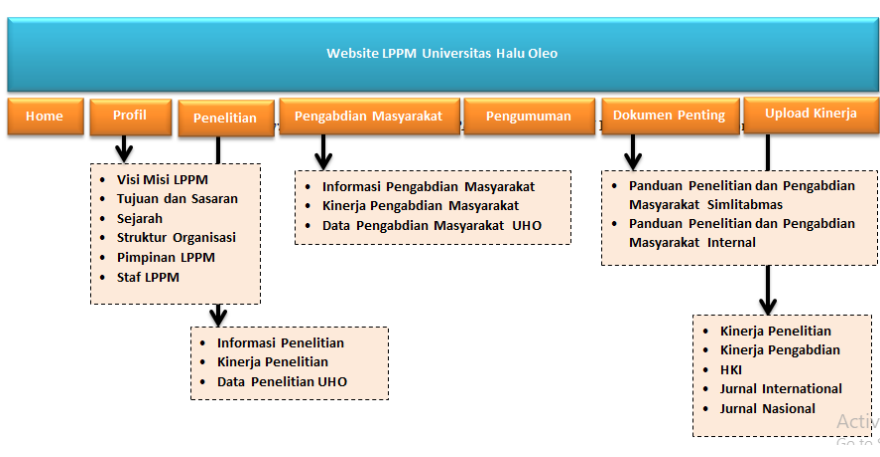

Gambar 2. Rancangan Peta situs

Pada Gambar 2 merupakan rancangan peta situs system informasi website LPPM dimana terdapat beberapa menu dan submenu, rancangan ini akan dimplementasi dalam bentuk website.

\section{B. Teknik Pengumpulan Data}

Pada kegiatan penelitian ini, menggunakan beberapa metode yang dijadikan sebagai cara pengumpulan data yang dibutuhkan, yaitu :

1. Metode Observasi

Observasi adalah mengamati secara langsung pelaksanaan kegiatan pada kantor LPPM Universitas Halu Oleo Kendari

2. Metode Wawancara

Wawancara adalah Tanya jawab secara langsung kepada pimpinan lembaga LPPM serta Staf LPPM juga Dosen lingkup universitas Halu Oleo

3. Kajian Pustaka

Penelitian ini dilakukan dengan cara mencari referensi yang berhubungan dengan Sistem Informasi LPPM dan teori penunjangnya.

\section{Analisis Kebutuhan Sistem}

a. Kebutuhan Antarmuka (Interface)

Kebutuhan antarmuka untuk perancangan ini sebagai berikut :

1) Sistem yang akan dibangun mempunyai tampilan yang familiar bagi user. 
2) Sistem menampilkan form login kepada user untuk mengakses aplikasi yang telah di integrasikan dengan internet.

b. Kebutuhan Fungsional

Penjelasan proses fungsi adalah suatu bagian yang berupa penjelasan secara rinci setiap fungsi yang digunakan untuk menyelesaikan masalah. Fungsifungsi yang dimiliki oleh aplikasi ini adalah :

1) Pengguna dapat login ke web

2) Pengguna dapat melihat seputar informasi LPPM

c. Kebutuhan Perangkat Keras

Berikut ini spesifikasi perangkat keras (hardware) yang digunakan dalam mengembangkan sistem informasi, yakni :

PC dengan spesifikasi :

- Intel(R) Core(TM)2 Duo CPU T5870 @2.00GHz

- 2 GB DDR2 Memory

- 500 GB HDD

d. Kebutuhan Perangkat Lunak

Selain perangkat keras, dibutuhkan juga perangkat lunak (software) dalam pengembangan sistem ini, antara lain :

- Sistem operasi Windows 7 Ultimate

- Xampp

- Mysql

- Dreamweaver

- Notepad

- Image Editing

CMS Wordpress

Notepad

\section{Lokasi Penelitian}

Penelitian bertempat di LPPM Universitas Halu Oleo serta untuk perancangan dan penbuatan sistem dilakukan di Lab Pemrograman dan komputasi Teknik Elektro Universitas Halu Oleo.

\section{HASIL DAN PEMBAHASAN}

\section{A. Desain Frontend}

Hasil yang diperoleh setelah melakukan rancang bangun system informasi adalah sebuah system informasi yang dapat diakses melalui http://lppm.uho.ac.id jika diakses maka akan tampil home page seperti gambar di bawah.
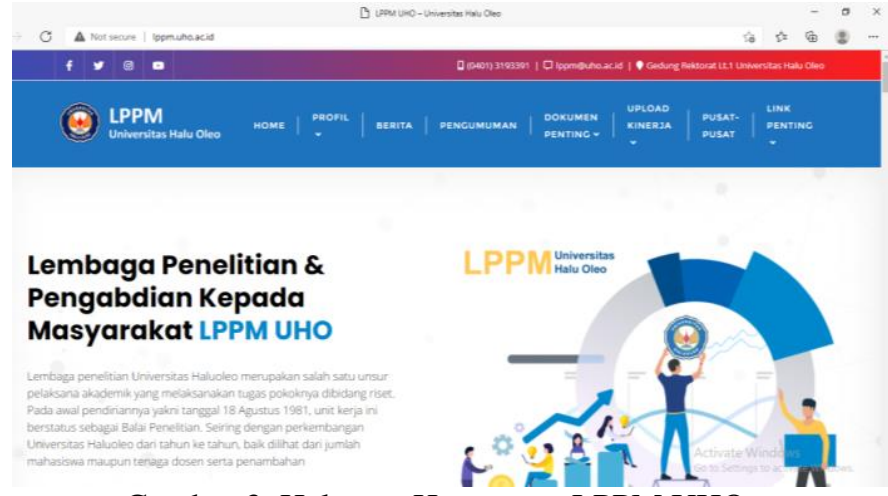

Gambar 3 Halaman Homepage LPPM UHO

\section{B. Konten}

\section{IPPM News}
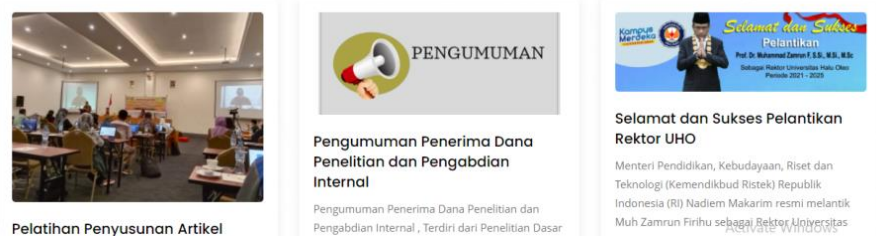

Gambar 4 Halaman Berita

Terdapat beberapa halaman dan menu pada system informasi website yang telah dirancang seperti pada gambar 4 merupakan halaman berita yang memuat informasi berita seputar kegiatan penelitian dan pengabdian masyarakat universitas halu oleo

\section{Sidebar}

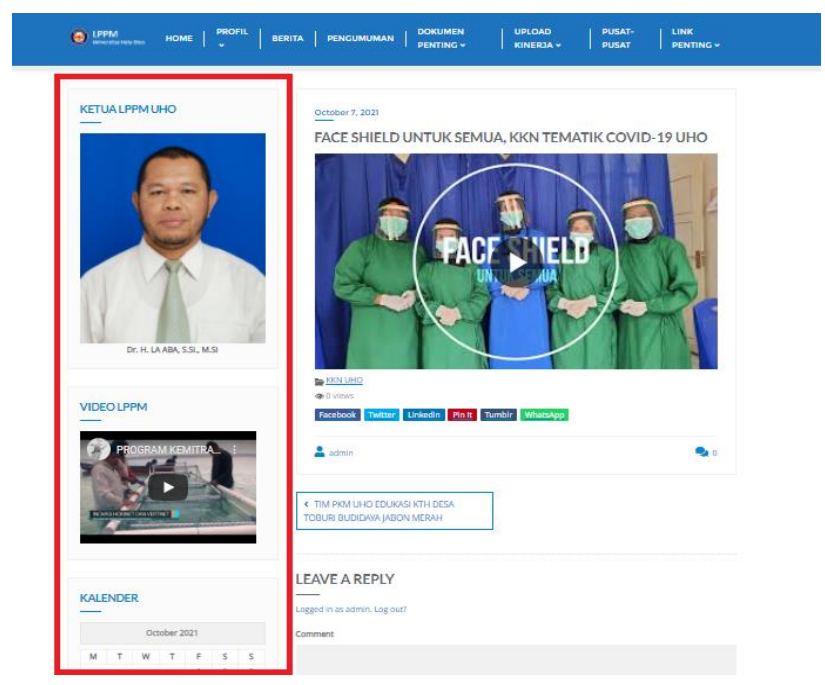

Gambar 5 Sidebar Web LPPM 
Pada website hasil rancangan ini terdapat sidebar dibeberapa halaman yang memuat informasi foto maupun video serta link ke beberapa menu dan arsip berita.

\section{Desain Backend}

\section{Halaman Admin}

Untuk masuk halaman admin web LPPM klik https://lppm.uho.ac.id/wp-admin maka kan muncul halaman admin

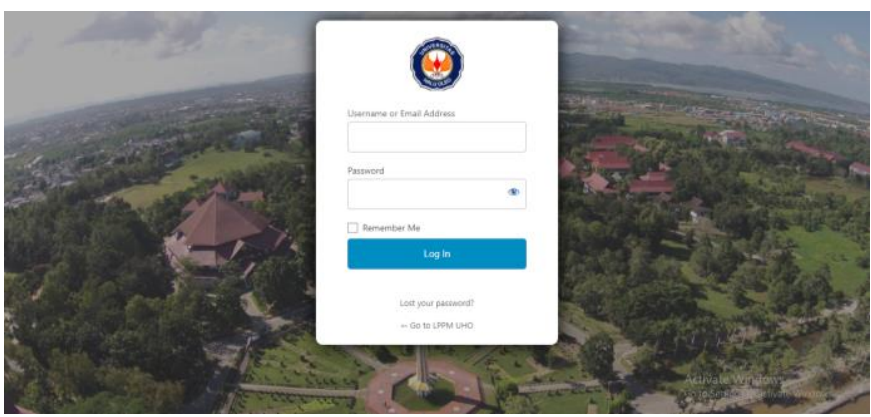

Gambar 6 Halaman Login Admin

Masukkan Username dan Password Admin -> Klik Login Setelah masuk akan tampil halaman Dashboard

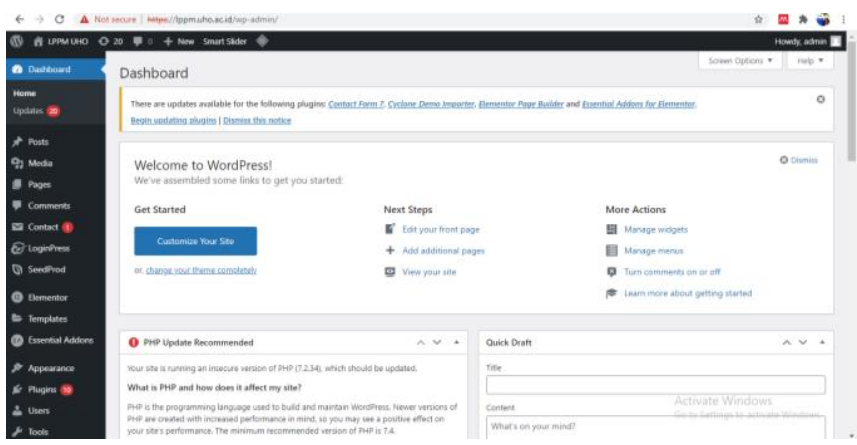

Gambar 7 Halaman Dashboard

\section{E. Pengujian Sistem}

Pengujian Sistem dilakukan untuk mengetahui apakah sistem berjalan dengan baik atau tidak, jenis pengujian menggunakan metode black box yaitu menguji pada fungsional sistem, berikut ini hasil pengujian sistem informasi :
Tabel 1 Hasil Pengujian Sistem

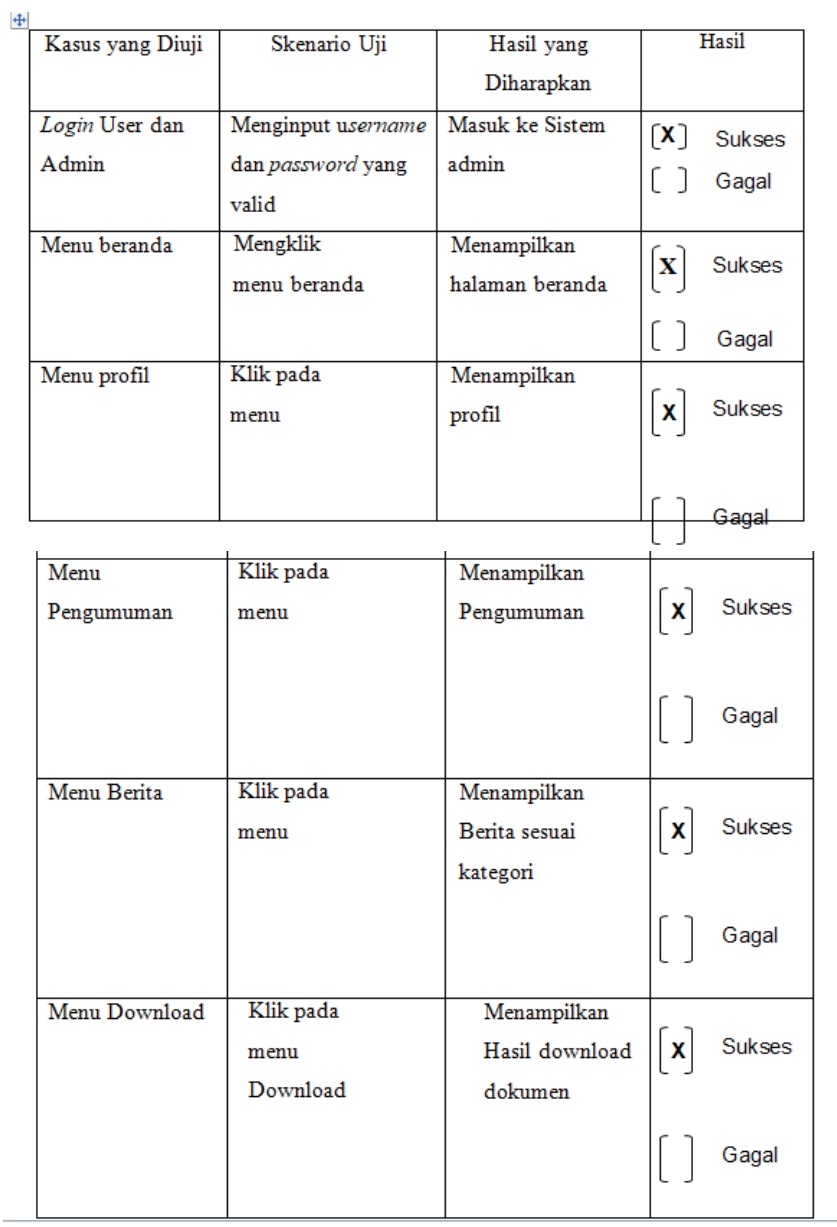

Selanjutnya pada pengujian penggunaan sistem dilakukan uji coba terhadap 3 (tiga) jenis pengguna yaitu, (1) Admin LPPM (2) User LPPM (3) User Umum, hasil dari pengujian dapat disimpulkan pada tabel dibawah ini :

Tabel 2 Uji coba pengguna

\begin{tabular}{|l|l|l|}
\hline No & Pengguna & Hasil Uji Coba \\
\hline 1 & Admin LPPM & $\begin{array}{l}\text { Dapat login pada sistem dengan baik serta } \\
\text { telah dapat menginput berita dan upload } \\
\text { dokumen }\end{array}$ \\
\hline 2 & User LPPM & $\begin{array}{l}\text { Dapat login pada sistem dengan baik serta } \\
\text { telah dapat menginput berita dan upload } \\
\text { dokumen }\end{array}$ \\
\hline 3 & User Umum & Dapat mengakses seluruh menu dengan baik \\
\hline
\end{tabular}

\section{KESIMPULAN}

Dari hasil penelitian ini telah menghasilkan system informasi website Lembaga Penelitian dan Pengabdian Kepada Masayarakat LPPM Universitas Halu Oleo, system telah di uji dengan hasil dapat berjalan dengan baik serta 
website telah dapat diakses secara online melalaui link lppm.uho.ac.id.

\section{DAFTAR ACUAN}

[1] D. Ratnasari, H. A. Tawakal, and M. Kom, "ANALISIS DAN PERANCANGAN APLIKASI SISTEM INFORMASI PENELITIAN DAN PENGABDIAN MASYARAKAT LPPM STT TERPADU NURUL FIKRI,” Jan. 2017. Accessed: Apr. 18, 2021. [Online]. Available: www.yiiframework.com.

[2] R. Agustino, Y. B. Widodo, A. Wiyatno, and M. I. Saputro, "Sistem Informasi Penelitian dan Pengabdian Masyarakat di Universitas Mohammad Husni Thamrin," J. Jaring SainTek, vol. 2, no. 1, pp. 1-12, Jun. 2020, doi: 10.31599/jaring-saintek.v2i1.61.

[3] I. Widaningrum, Perancangan Sistem Informasi Penelitian dan Pengabdian Dosen. 2016.
[4] Y. Dan and A. Jananto, "Rancang Bangun Sistem Informasi Penelitian dan Pengabdian kepada Masyarakat," J. Teknol. Inf. Din., vol. X, no. 2, pp. 84-95, 2005, Accessed: Apr. 18, 2021. [Online]. Available: https://www.unisbank.ac.id/ojs/index.php/fti1/article/view $/ 15$.

[5] A. Kurniawan, "23 Pengertian Sistem Informasi Menurut Para Ahli Dan Contohnya," https://www.gurupendidikan.co.id/pengertian-sisteminformasi/, 2021.

https://www.gurupendidikan.co.id/pengertian-sisteminformasi/ (accessed Apr. 21, 2021)

[6] E. Billah and E. Billah, "Pengertian dan Tahap Metode SDLC Waterfall | by Ersandi Billah | Medium," https://medium.com/, 2019.

https://medium.com/@ersandibillah03/sdlc-waterfall3a3c893be77b (accessed Apr. 21, 2021). 